Forum $2020 \cdot 35: 62$

https://doi.org/10.1007/s12312-019-00726-6

Online publiziert: 29. November 2019

(c) Springer Medizin Verlag GmbH, ein Teil von

Springer Nature 2019

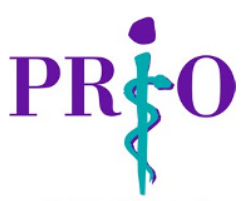

Prävention und

integrative Onkologie

PRIO in Kooperation mit dem Hautkrebsnetzwerk Deutschland

\title{
Sinnvolle begleitende Therapien für Patienten mit Krebs
}

\section{Broschüre erschienen}

en Broschüre der Hautkrebs-Netzwerks Deutschland e. V., die durch eine Projektförderung durch die Techniker Krankenkasse möglich wurde, wird laienverständlich erklärt, was komplementäre Medizin ist und welche Chancen und Risiken bestehen. Patient*innen und Angehörige finden hier einen Wegweiser in die Methoden der Komplementären oder Alternativen Medizin von Traditionellen Medizinsysteme zu Mind-Body-Therapien und den Substanzgebundenen Methoden mit einer alphabetischen Übersicht, zu den häufigsten nachgefragten Methoden. Die Frage Was man gegen die häufigsten Beschwerden und Nebenwirkungen tun kann, wird ebenso beantwortet, wie die Frage, was gesunde Ernährung eigentlich ist und warum Körperlichen Aktivität das $\mathrm{A}$ und $\mathrm{O}$ der begleitenden Therapien ist.

Broschüre und DVD sollen Mut machen, sich auf den Weg zu begeben und selber aktiv zu werden. Die Broschüre/DVD können kostenlos bestellt werden bei Frau Backes, Hautkrebs-Netzwerk Deutschland (a.backes@hautkrebs-netzwerk.de) bzw. unter www.hautkrebs-netzwerk.de heruntergeladen werden.

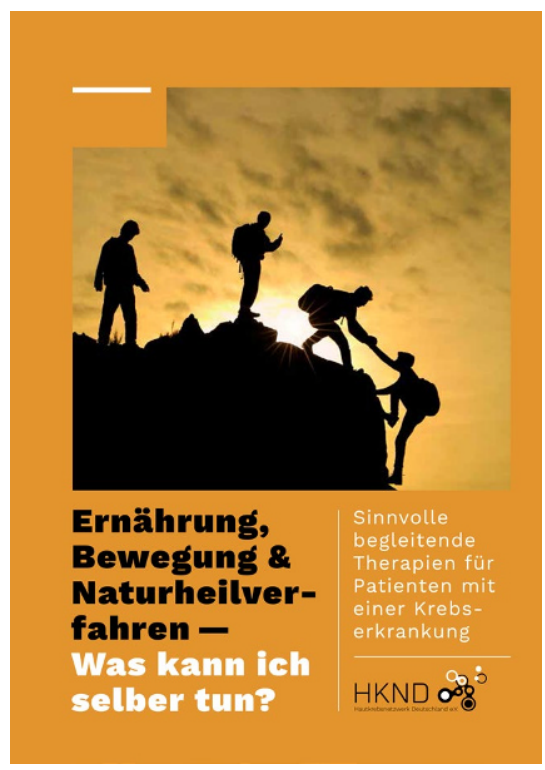

\section{Korrespondenzadresse}

\section{J. Hübner}

Klinik für Innere Medizin II Am Klinikum 1, 07747 Jena, Deutschland jutta.huebner@med.uni-jena.de 